\title{
The social toll of inflammatory bowel disease
}

\author{
RICHARD G FARMER MD MACP MACG
}

RG FARMER. The social toll of inflammatory bowel disease. Can J Gastroenterol 1994;8(7):433-437. Inflammatory bowel disease (IBD) - ulcerative colitis and Crohn's disease - has become one the most important chronic digestive disorders found in the younger population. As a result of the nature of the illness, with remission and exacerbation of the inflammatory process, there has been increasing concern regarding the costs, both financial and social, of IBD. There have been attempts to quantify disease activity and to assess the results of treatment and the ability of the patient to function in society. As a result, there has been an increased interest in the 'social toll' of IBD. Beginning in 1988, and using a direct interview technique, ambulatory patients with IBD were evaluated for quality of life at the Cleveland Clinic Foundation. Included were patients whose disease had been present for about 10 years, and both surgical and nonsurgical patients. The interview questionnaire consisted of 47 items in four categories: functional/economic, social/recreational, affect/life in general and medical/symptoms. Patients with ulcerative colitis had better quality of life than those with Crohn's disease and patients without surgery had better quality of life than those who had undergone surgery. Over the ensuing five-year period, it was shown that quality of life measures are of value in assessing the results of medical and surgical therapy, and the measures frequently give information not usually obtained by physicians and have implications for quality assurance and outcome measurement.

Key Words: Crohn's disease, Follow-up, Inflammatory bowel disease, Prognosis, Quality of life, Ulcerative colitis

\section{Coûts sociaux des maladies inflammatoires de l'intestin}

RÉSUMÉ : Les maladies inflammatoires de l'intestin (MII), colite ulcéreuse et maladie de Crohn, se classent parmi les plus importantes maladies digestives chroniques chez les jeunes. Compte tenu de la nature de la maladie, qui s'accom-

voir page suivante

\section{Agency for International Development, Washington, DC, USA}

Correspondence: Dr RG Farmer, Clinical Professor of Medicine, Georgetown University Medical Center, 3800 Reservoir Road NW, Washington, DC 20007-2197, USA. Telephone (202) 687-6581, Fax (202) 687-6545

This paper was presented at the Trends in Inflammatory Bowel Disease Therapy meeting, April 6 to 9, 1994, held in Victoria, British Columbia. This paper has also been published in Sutherland LR, et al, eds. Inflammatory Bowel Disease: Basic Research, Clinical Implications and Trends in Therapy. Boston, Dordrecht and London: Kluwer Academic Publishers, 1994
$\mathrm{T}$ HE 'HUMAN COST' OF INFLAMMA tory bowel disease (IBD) is not easily assessed or quantified. The most obvious measure would be premature death, but this occurs in fewer than $5 \%$ of IBD patients (1). The second most obvious measure would be the number of operations or some assessment of disease severity. However, as is well known $(2,3)$, IBD - both ulcerative colitis and Crohn's disease - is characterized by unpredictability of exacerbation and remission. Since most patients afflicted are diagnosed between the ages of 15 and 35 years (4), and with the low mortality rate, efforts have been made to quantify various elements associated with morbidity. Since patients with IBD often are found in higher socioeconomic groups than the general public (5), the loss of work and income can also be used; however, these measures are exceedingly difficult to assess.

In recent years, attempts have been made to quantify disease activity as well as quality of life assessment for patients with IBD (6-8). These measures have proved elusive, as they are usually from the medical (or the physician's) perspective, and emphasis is often placed on symptoms and clinical findings $(9,10)$. A major complicating factor in such assessments has been the unpredictable nature of the disease on the one hand and the presumed psychological aspects on the other (11). 
pagne de rémissions et d'exacerbations du processus inflammatoire, on s'inquiète de plus en plus des coûts tant financiers que sociaux des MII. On a tenté de mesurer le degré d'activité pathologique et d'évaluer les résultats des traitements, ainsi que la capacité du patient à fonctionner en société. Il en est résulté un intérêt grandissant pour les coûts sociaux des MII. Dès 1988, à l'aide d 'une technique d'interview directe, des patients non hospitalisés atteints de MII ont été évalués quant à leur qualité de vie à la Cleveland Clinic Foundation. Les patients admis à l'étude souffraient de cette maladie depuis une dizaine d'années et avaient ou non été opérés. Le questionnaire comportait 47 éléments répartis en quatre catégories : fonctionnel/économique, social/récréatif, affectif/vie en général et médical/symptômes. Les patients atteints de colite ulcéreuse avaient une meilleure qualité de vie que les patients atteints de maladie de Crohn, et les patients qui n'avaient pas été opérés avaient une meilleure qualité de vie que les patients qui avaient subi une chirurgie. Au cours de la période de cinq ans qui s'ensuivit, on a pu démontrer que les mesures de la qualité de vie sont utiles pour évaluer les résultats des traitements médicamenteux et chirurgicaux, et ces mesures donnent souvent des renseignements que l'on n'obtient pas habituellement auprès des médecins et ont une certaine portée sur l'assurance de la qualité et la mesure du pronostic.

\section{TABLE 1}

Inflammatory bowel disease: Costs of illness

\section{Crohn's disease}

Average annual medical cost per patient in $1990=$ US $\$ 6,561$

Total annual medical cost $=$ US\$1.0-1.2 billion

\section{Ulcerative colitis}

Annual medical cost per patient in $1990=$ US\$1,488

Total annual medical cost $=$ US\$0.4-0.6 billion

Adjusting for productivity losses - annual economic cost for inflammatory bowel disease $=$ US\$1.8-2.6 billion

Top $2 \%$ of Crohn's patients accounted for $34.3 \%$ of total amount

Based on reference 14

There have been attempts to define more accurately and scientifically the various aspects of quality of life for patients with IBD. Garrett and Drossman (12) defined the 'biological and behavioral considerations' of the health status of patients with IBD to include the following: disease activity, psychological state, cultural influences, social support, effects of complications, previous surgery and medications. Drossman et al (13) also described the 'functional states and patient worries' in IBD using a specific instrument for detection. They observed that IBD patients experienced moderate functional impairment but more in the social and psychological sphere than in the physical dimensions, Crohn's disease patients have more psychological dysfunction than ulcerative colitis patients and IBD patients generally have their greatest concerns regarding the females as it was for either male patients or older persons with IBD; however, the vast majority of patients remained employed, although functioning suboptimally.

In attempts to define and quantify the quality of life for patients with IBD, attention has focused primarily on the results of surgery, particularly for patients with ulcerative colitis. McLeod et al (16) showed that there was no significant difference in quality of life for the type of operation for patients with ulcerative colitis (pouch or standard ileostomy) but that generally quality of life improved after surgery. Likewise, Sagar et al (17) noted that in medically treated patients with ulcerative colitis, those who had undergone (presumably curative) surgery had a better quality of life, and there was more depression and limitation of social activity in patients who were treated medically.

The pelvic pouch operation had understandably received specific attention in terms of quality of life assessment, and Tjandra et al (18) from the Cleveland Clinic described similar functional results among patients who had undergone this procedure for ulcerative colitis and those who had undergone it for familial polyposis. In a large study from the Mayo Clinic (19) encompassing 240 patients over an eight-year period, it was noted that overall quality of life was satisfactory and patients were able to function reasonably well by comparison with their peers $90 \%$ of the time.

Assessment of the quality of life for patients following medical therapy has been more difficult to accomplish and Irvine and colleagues $(8,9)$ have had a particular interest in assessing the results of clinical trials. In a recent study of 305 patients with IBD, a multicentre study of cyclosporine versus placebo was carried out using a quality of life instrument as a measure of therapeutic efficacy (20). This study showed that quality of life assessment compared well with the Crohn's disease activity index (6) and correlated with the clinical assessment quite satisfactorily. Thus, a number of recent studies have indicated the value of quality of life assess-
TABLE 2 Inflamme

Category

Ihave

1. Thave

2. $1 \mathrm{am}$

4. $\mathrm{lam}$

5. I feel

6. Mye

7. Myd

8. Mys)

9. In co

10. I am

11. I feel

12. My g

II Socic

1. I am

2. I hav

3. I feel

4. I car

5. Ifeel

6. I car

7. I car

8. I am

9. The

10. I bel

11. I fee

12. I fee

13. Myc

14. Myc

15. I pa

III Affe

1. I ha

2. Mos

3. I ha

4. Myl

5. Whe

6. I fes

7. $1 \mathrm{loc}$

8. Ifre

9. In C

10. I fin

11. Oth

IV Me

1. I We

2. I fin

3. My

4. I he

5. My

6. Ihc

7. Ita

8. Ito permanently disabled $(11,15)$. In a German study (15), it was noted that the expense associated with treating the disease was twice that among young 


\section{TABLE 2}

\section{Functional/economic}

1. I have been able to fulfil my educational goals

2. I am able to support myself and my family.

3. I am receiving financial support from a source other than from my employment

4. I am having difficulty getting insurance

5. I feel that I am able to get through each day as well as others

6. My earnings are as good as others in similar jobs or activities

7. My disease has made it difficult for me to obtain a job

8. My symptoms interfere with my job or activities

9. In comparing myself to others, I feel I have less energy

10. I am able to carry out my regular activities in a way satisfying to me

11. I feel I have been able to move ahead in my job, family responsibilities or school

12. My growth and physical development were affected by my illness

\section{Social/recreational}

1. I am able to enjoy activities with my family

2. I have someone to talk to about the way I feel

3. I feel isolated because of my disease

4. I cancelled an activity/activities this past month because of symptoms

5. I feel frightened by the future

6. I can participate in social activities with friends

7. I can depend on my family or friends for support

8. I am able to participate in a recreational/sport activity regularly

9. The physical activity I participate in at least once a week is (fill in):

10. I belong to and participate regularly in a club/church/professional organization

11. I feel satisfied with my relationship with my spouse or significant other

12. I feel satisfied about the way I participate in family activities

13. My disease has made it difficult for me to have a family

14. My condition has made it difficult for me to share intimate relationships

15. I participate in a hobby or special interest in addition to my other tasks

\section{Affect/life in general}

1. I have made plans for things to do next month

2. Most of the time I sleep through the night

3. I have made plans for things I'll be doing a year from now

4. My life is going along pretty much as I had planned

5. When compared with other persons of my age, I feel pleased with my accomplishments

6. I feel frustrated with my health problems

7. I look forward to each day

8. I frequently worry about my health

9. In comparison to other people, I feel I become more easily discouraged

10. I find that I need mood-elevating medications to help get me through the day

11. Others see me as chronically ill

IV Medical/symptoms

1. I would describe my general physical condition in comparison to others as (fill in):

2. I find myself preoccupied with what I eat

3. My symptoms significantly affect the way I function each day

4. I have abdominal pain frequently

5. My diarrhea is disruptive (ie, does it interfere with your daily life?)

6. I have difficulty maintaining my weight

7. I take medications

8. I take the following medications once a day (fill in):

9. Do you feel your doctor has been supportive and understanding of your feelings?

This table is copyright 1989, Richard G Farmer, MD. Cleveland Clinic Foundation. + Response marginally significant $(0.05 \leq P \leq 0.01)$; ++ Response statistically significant ( $P \leq 0.01)$ 
ment, but the optimal instrument to assess and quantify quality of life continues to a challenge.

Because of a long term interest in IBD (21) and a registry of patients developed over 15 to 20 years, the author's group were able to develop cohorts of patients followed at the Cleveland Clinic Foundation whose quality of life could be measured (22). The study group consisted of 164 patients with IBD, both ulcerative colitis and Crohn's disease, with or without operation. Patients selected had IBD for approximately 10 years, with disease onset at about age 20 .

To ensure applicability to out-patient care, the survey questionnaire was designed for use with ambulatory patients who are functioning in society; this characterizes most patients with IBD $(3,4)$. Therefore, questions assess activities of daily living rather than focusing on either medical or psychological issues.

Four broad categories of questions were developed for the IBD questionnaire (Table 2):

- functional/economic - the ability to function in work, school, and home, to support self and others, and to advance professionally;

- social/recreational - interpersonal relationships including those with spouse or significant other and family, sexual relationships, relationships in social settings, and ability to perform recreational, leisure, and social activities;

- affect/life in general - attitude towards life and health, presence of optimism or pessimism (eg, depression) and ability to plan for the future; and

- medical-gastrointestinal and other symptoms, use of medication, history of surgery, interaction with health care professionals and relationship with physician.

Answers were scored using the Likert scale of 1 to 5 (strongly agree to strongly disagree). Questions were phrased both positively and negatively to avoid repetition of answers.
The survey was administered during a two-month period in 1988 and was repeated as a one-year follow-up in 1989. The author's group experience with long term follow-up studies discouraged using physicians to administer the survey because of their orientation towards clinical manifestations of disease and treatment. The 47 questions were administered by nonphysician interviewers in person or by telephone. Questions were short, grammatically simple and free from clinical terminology. Completion took 15 to 20 mins. The instrument could also be used as a self-administered questionnaire.

Univariate analysis of 45 instrument questions to determine whether scores differed by group (ulcerative colitis, surgery; ulcerative colitis no prior surgery; Crohn's disease, surgery; Crohn's disease, no prior surgery) resulted in 18 questions yielding statistically significant or marginally significant results (22). The other two questions listed multiple physical activities and medications, and were reported descriptively. The scores indicate that:

- patients with ulcerative colitis have a better quality of life than patients with Crohn's disease $(\mathrm{P}<0.009)$. (Additionally, surgery impacted the score $[\mathrm{P}<0.003]$. There was no interactive effect between disease and surgery);

- nonsurgical ulcerative colitis patients have a better quality of life than both surgical ulcerative colitis patients and Crohn's disease patients regardless if the latter group has undergone surgery;

- nonsurgical Crohn's disease patients have a better quality of life than surgical Crohn's disease patients;

- Crohn's disease patients who have undergone surgery have the worst quality of life compared with the other three categories; and

- the score by disease group suggests a possible need for closer surveillance for surgical Crohn's disease patients (compared with the other groups).

Before completion of the quality of life assessment of ambulatory patients with IBD, further comparisons were made with patients similar in age and other chronic diseases, using the same survey instrument. Comparison using the quantifiable quality of life for patients with rheumatoid arthritis and multiple sclerosis was completed (23); comparison was made among patients whose chronic illness had begun at approximately age 20 and had been present for approximately 10 years, thus enabling general comparison among the three groups. It was observed that the quality of life for patients with multiple sclerosis was the poorest, followed by patients with rheumatoid arthritis; quality of life of IBD patients was the best among the three groups studied. It was further noted that there was a discrepancy between the functional assessment by the physician and the quality of life by the patient, particularly in multiple sclerosis (observed previously in IBD) $(12,22)$.

Thus, while the survey instrument was designed specifically for patients with IBD, the impact on the quality of life of patients with other chronic illnesses can also be assessed and can provide the physician and other members of the health care team, particularly nurses, physical and occupational therapists, and social workers, with helpful information regarding the response to therapy, the overall functioning of the patient and an assessment of the 'natural history' of these important chronic diseases.

In summary, attempts to quantify the quality of life for patients with IBD (and other chronic illnesses) can provide valuable information not generally recognized by health care professionals nor assessed by physicians both in terms of assessing the results of medical and surgical therapy as well as attempting to define the 'natural history' of the diseases. Quality of life measurement can be useful and provide additional information not usually obtained in the course of medical followup studies. 


\section{REFERENCES}

1. Farmer RG, Hawk WA, Turnbull RB. Clinical patterns in Crohn's disease. A statistical study of 615 patients. Gastroenterology 1975;68:627-35.

2. Farmer RG, Whelan G, Fazio VW. Long-term follow-up of patients with Crohn's disease. Gastroenterology 1985;88:825-33.

3. Farmer RG. Ulcerative colitis. History and epidemiology; clinical features; endoscopy; clinical types and differential diagnosis; complications; medical management. In: Haubrick WS, Kalser MH, Roth JLA, Schaffner F, eds. Bockus Gastroenterology, 4th edn. Philadelphia: WB Saunders Co, 1985:2137-9,2153-7,2179-207.

4. Hellers G. Crohn's disease in Stockholm County. 1955-1974. A study of epidemiology, results of surgical treatment and long term prognosis. Acta Chir Scand 1979;490(S):1-84.

5. Gazzard BG. The quality of life in Crohn's disease. Gut 1987;28:378-81.

6. Best WR, Becktel JM, Singleton JW. Development of a Crohn's Disease activity index: national Cooperative Crohn's Disease Study.

Gastroenterology 1976;70:439-44.

7. Drossman DA, Patrick DL, Mitchell CM, Zagami EA, Applebaum MI. Health related quality of life in inflammatory bowel disease: Functional status and patient worries and concerns. Dig Dis Sci 1989;34:1379-86.
8. Mitchell A, Guyatt G, Singer J, et al. Quality of life in patients with inflammatory bowel disease. J Clin Gastroenterol 1988;10:306-10.

9. Guyatt G, Mitchell A, Irvine EJ, et al. A new measure of health status for clinical trials in inflammatory bowel disease. Gastroenterology 1989;96:804-10.

10. Scholmerich J, Sedlak P, Hoppe-Seyler $\mathrm{P}$. The information needs and fears of patients with inflammatory bowel disease. Hepatol Gastroenterol 1987;34:182-5.

11. Sorensen VZ, Olsen BG, Binder V. Life prospects and quality of life in patients with Crohn's disease. Gut 1987;28:382-5.

12. Garrett JW, Drossman DA. Health status in inflammatory bowel disease. Biological and behavioral considerations. Gastroenterology 1190;99:90-6.

13. Drossman DA, Patrick DL, Mitchell $\mathrm{CM}$, et al. Health-related quality of life in inflammatory bowel disease. Functional status and patient worries and concerns. Dig Dis Sci 1989;34:1379-86.

14. Hay JW, Hay AR. Inflammatory bowel disease: Costs of illness. J Clin Gastroenterol 1992;14:309-17.

15. Sonnenberg A. Disability and need for rehabilitation among patients with inflammatory bowel disease. Digestion 1992;51:168.

16. McLeod RS, Churchill DN, Lock AM, et al. Quality of life of patients with ulcerative colitis, preoperatively and post-operatively. Gastroenterology 1991;101:1307-13.

17. Sagar PM, Lewis W, Holdsworth PJ. Quality of life after restorative proctocolectomy with a pelvic ileal reservoir compares favorably with that of patients with medically treated colitis. Dis Colon Rectum 1993;36:584.

18. Tjandra JJ, Fazio VW, Church JM, et al. Similar functional results after restorative proctocolectomy in patients with familial adenomatous polyposis and mucosal ulcerative colitis. Am J Surg 1993; 165:322.

19. Kohler LW, Pemberton JH, Hodge DO, et al. Long term functional results and quality of life after ileal pouchanal anastomosis and colectomy. World J Surg 1992;16:1126-31.

20. Irvine EJ, Feagan B, Rochon J, et al. Quality of life: a valid and reliable measure of therapeutic efficacy in the treatment of inflammatory bowel disease. Gastroenterology 1994;106:287-96.

21. Farmer RG. Inflammatory bowel disease in tertiary referral center: The Cleveland Clinic Experience. Can J Gastroenterol 1988;2S:89-94.

22. Farmer RG, Easley KA, Farmer JM. Quality of life assessment of patients with inflammatory bowel disease. Cleve Clin J Med 1992;59:35-42.

23. Rudick RA, Miller D, Clough JD, et al. Quality of life in multiple sclerosis, comparison with inflammatory bowel disease and rheumatoid arthritis. Arch Neurol 1992;49:1237-42. 


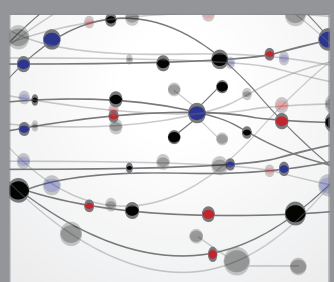

The Scientific World Journal
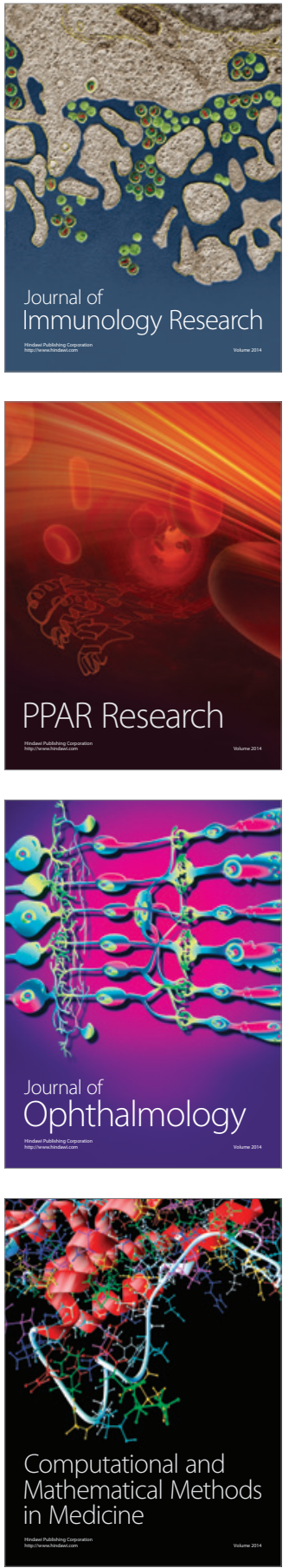

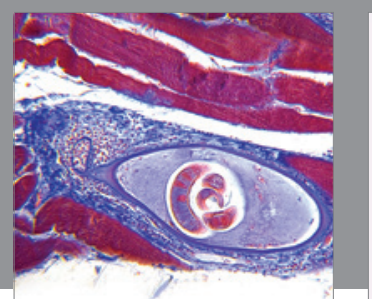

Gastroenterology Research and Practice

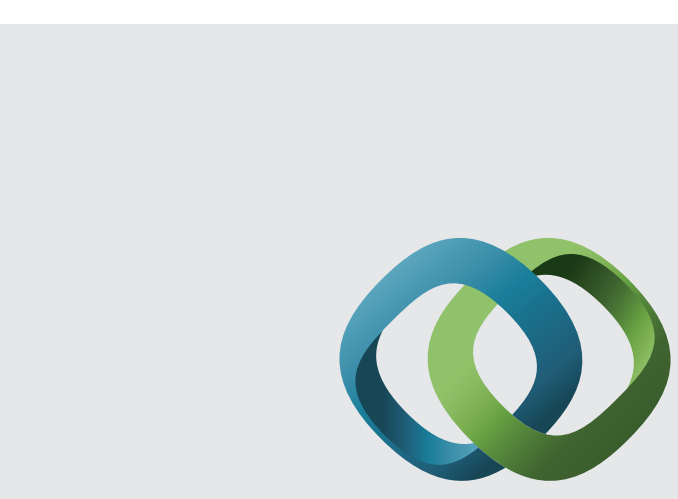

\section{Hindawi}

Submit your manuscripts at

http://www.hindawi.com
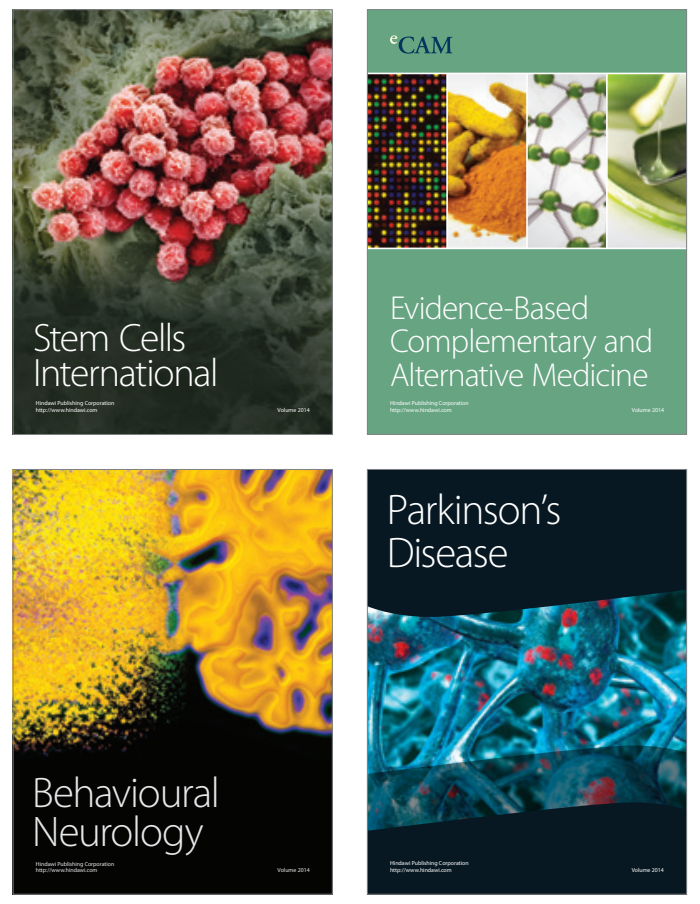
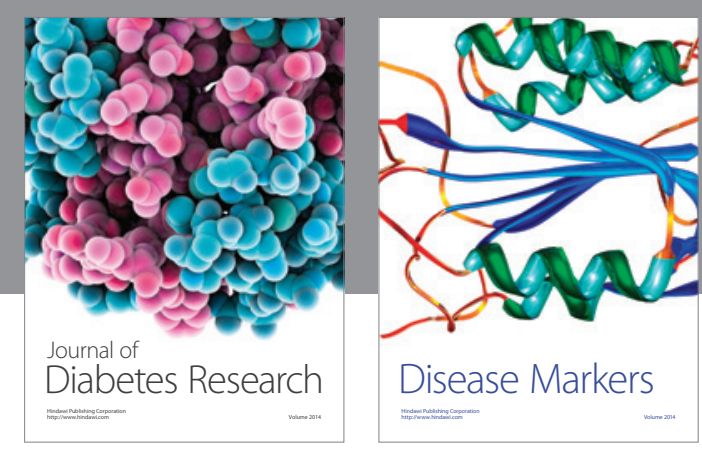

Disease Markers
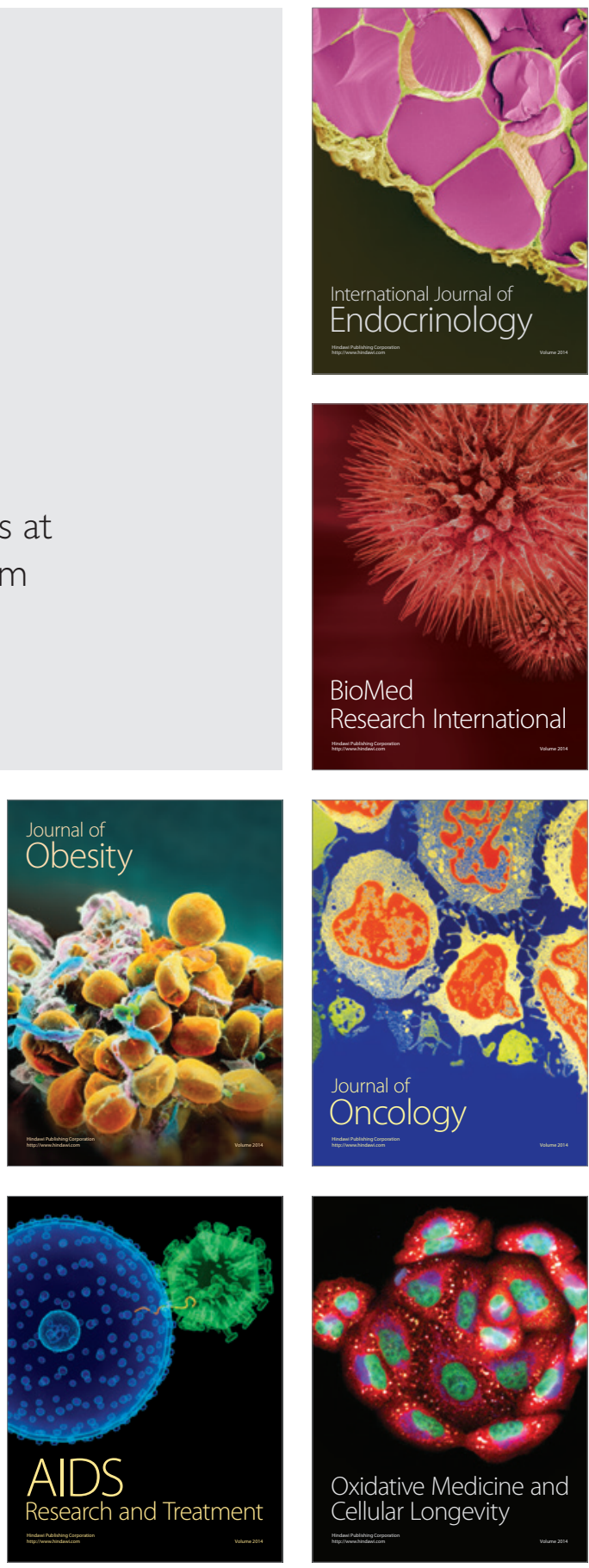